\title{
Process Variation Aware Wide Tuning Band Pass Filter for Steep Roll-Off High Rejection
}

\author{
Jian Chen and Chien-In Henry Chen \\ Department of Electrical Engineering, Wright State University, Dayton, OH 45435, USA \\ Correspondence should be addressed to Jian Chen; chen.92@wright.edu
}

Received 23 December 2014; Revised 13 March 2015; Accepted 20 March 2015

Academic Editor: Mohamed Masmoudi

Copyright ( 92015 J. Chen and C.-I. H. Chen. This is an open access article distributed under the Creative Commons Attribution License, which permits unrestricted use, distribution, and reproduction in any medium, provided the original work is properly cited.

A wide tuning band pass filter (BPF) with steep roll-off high rejection and low noise figure is presented. The design feature of steep roll-off high stopband rejection $(>20 \mathrm{~dB})$ and low noise figure $(<6 \mathrm{~dB})$ provides a wide tuning frequency span $(1-2.04 \mathrm{GHz})$ to accept desirable signals and reject close interfering signals. The process variation aware design approach demonstrates robustness of the BPF after calibration from process variations, operating in $1.04 \mathrm{GHz}$ tuning frequency span: almost zero deviation on center frequency, an average maximum deviation $1.16 \mathrm{~dB}$ on a nominal pass band gain of $55.6 \mathrm{~dB}$, and an average maximum deviation $1.06 \mathrm{MHz}$ on a nominal bandwidth of $12.3 \mathrm{MHz}$.

\section{Introduction}

When RF devices are upgraded to support future standards, IF amplifiers, mixers, band pass filters (BPFs), modulators, and demodulators are preferable to be tunable and costeffective to meet different frequency band standards [1]. Reconfigurable RF minimizes duplicated RF front-end components and hence reduces energy and cost. Considering cognitive radio in the TV bands, there are narrow spectral holes between strong TV transmitter signals. To avoid blocking of the receiver, strong TV signals have to be rejected by tunable BPF of high linearity, high $Q$, and high stopband rejection. A typical example is $Q=50$ for $10 \mathrm{MHz}$ bandwidth in a wide tuning frequency range of $500 \mathrm{MHz}$ in the TV bands. Reconfigurable RF devices include power amplifiers, antennas, band pass filters, and matching networks with high tuning speed and high linearity for reasons of size and cost.

Tunable BPF features include tunable frequency range, pass band gain, tuning center frequency span, bandwidth, noise figure, and stopband rejection. Several state-of-the-art CMOS design techniques such as gm-C filters, $Q$ enhanced LC filters, N-path, and pseudo-N-path filters have been presented. Most of them have either low band pass gain, high noise figure, or low tuning frequency range [2-15].
The gm-C filters have the advantage of low power and high frequency. Their weak linearity is improved by applying linearization techniques such as resistive source degeneration, dynamic source degenerated differential pair, tunable feedback, and adaptive feedback. However, these techniques have low pass band gain and narrow tuning range $[7,10]$. The Q-enhanced LC band pass filter through an adjustable negative-conductance generator is capable of operating in low-voltage supply but it has low pass band gain $(-5 \mathrm{~dB})$ and high noise figure $(26.8 \mathrm{~dB})$ [8]. Other $\mathrm{Q}$-enhanced LC filter based designs were proposed in $[9,11]$. The BPF in [9] consumes less power and has a tuning frequency range $(400 \mathrm{MHz})$ with a pass band gain $(23 \mathrm{~dB})$. A low pass band distortion BPF proposed in [11] has a low pass band gain $(0 \mathrm{~dB})$. The high-Q integrated switched capacitor band pass filter [12] has a broad frequency band but a low pass band gain $(-2 \mathrm{~dB})$ and high power. A design using high-Q N-path band pass filter is proposed [13], which has a tuning frequency range $(0.1-1 \mathrm{GHz})$ but low band pass gain $(-2 \mathrm{~dB})$. A novel inductorless tunable switched capacitor band pass filter based on $\mathrm{N}$-path periodically time-variant circuit operates in a high frequency range $(4-4.44 \mathrm{GHz})$ but has low pass band gain $(-12 \mathrm{~dB})$ and high noise figure $(14 \mathrm{~dB})[14]$. 


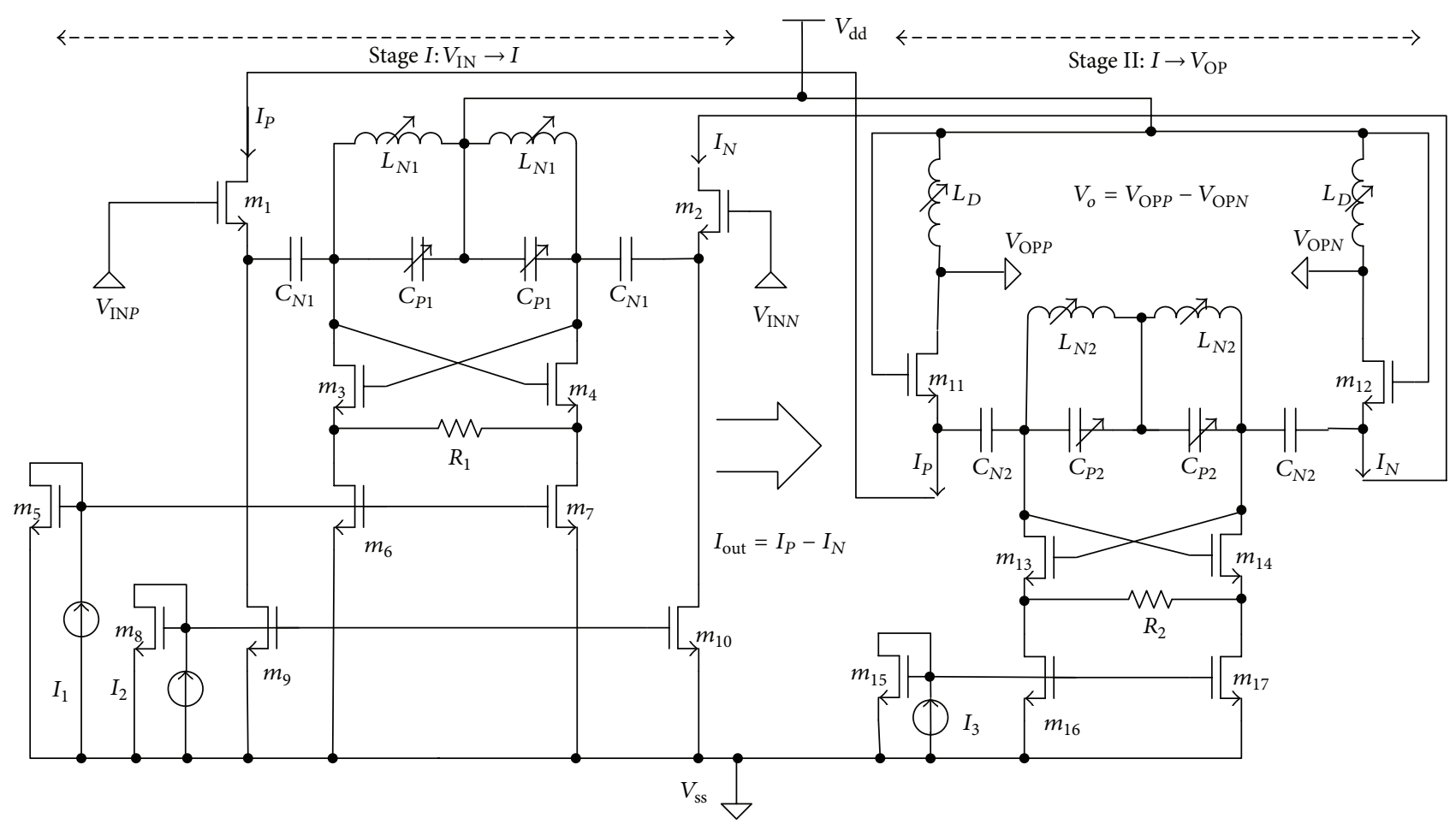

FIGURE 1: Schematic of band pass filter.

In this paper, a tunable BPF is presented, which has a wide tuning range, high band pass gain, high stopband rejection, low noise figure, and low power. The paper is organized as follows. Section 2 presents the architecture and operation principle of the tunable BPF. Section 3 presents design approach to BPF for specified center frequency and bandwidth. Section 4 presents process variation aware design approach to BPF for tunable center frequency and bandwidth. BPF design calibration after process variation is also presented. Section 5 presents measurements and performance analysis of BPF after design calibration. Section 6 is the conclusion.

\section{BPF Architecture and Principle Operation}

The tunable BPF with differential cascade architecture is divided into two stages. Stage I is the transconductance stage. Stage II is the transimpedance stage. The transconductance stage converts input voltages $V_{\text {INP }}$ and $V_{\text {INN }}$ to output currents $I_{P}$ and $I_{N}$ while the transimpedance stage converts input currents $I_{P}$ and $I_{N}$ to output voltages $V_{\mathrm{OPP}}$ and $V_{\mathrm{OPN}}$, as shown in Figure 1. The BPF is a type of double notch filter [2], which has two single notch filters with LC parallel series resonant combination, as depicted in Figure 2.

The input LC impedance for parallel series resonant combination is expressed as $Z_{N}$. Its small equivalent signal model is depicted in Figure 3, where the drain current $I_{D}$ of transistor $m_{9}$ (Figure 1) serves as driver of the amplifier and $I_{N}$ is the current feeding the LC parallel series resonant combination. $I_{L}$ is the current through transistor $m_{1}$. The transconductance of $m_{1}$ is $g_{m 1}$ and the load resistance seen

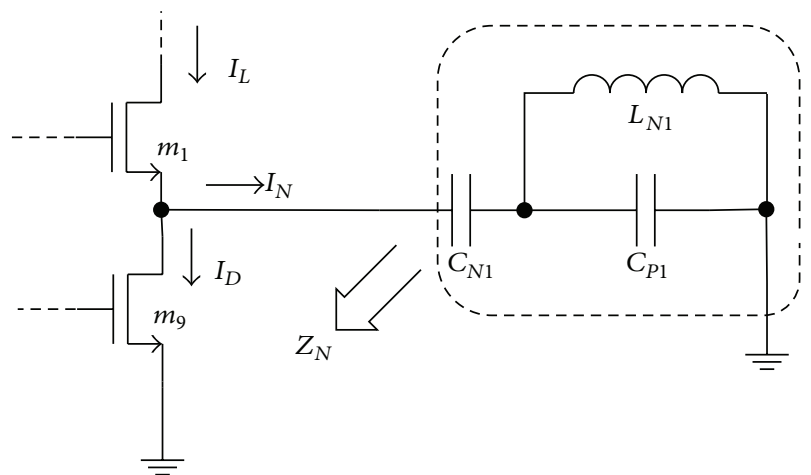

FIGURE 2: Schematic of single notch filter.

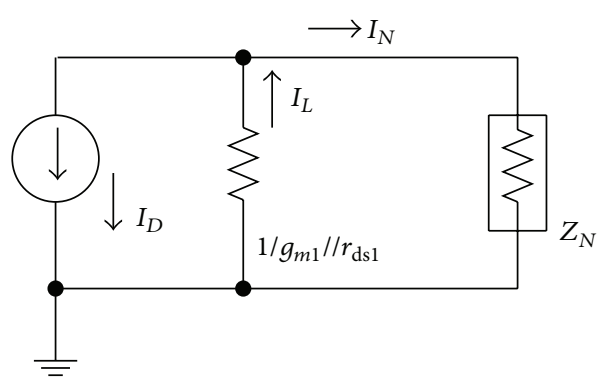

FIGURE 3: Small equivalent signal model for single notch filter.

from the source of $m_{1}$ is $1 / g_{m 1}$. The input impedance $Z_{N 1}$ is expressed in (1). Consider

$$
Z_{N 1}=\frac{1+s^{2} L_{N 1}\left(C_{N 1}+C_{P 1}\right)}{S C_{N 1}\left(1+s^{2} L_{N 1} C_{P 1}\right)}
$$


Considering the parallel series LC network, its parallel resonant frequency $f_{P 1}$ is higher than the zero frequency $f_{Z 1}$, as shown below:

$$
\begin{gathered}
f_{P 1}=\frac{1}{2 \pi \sqrt{L_{N 1} C_{P 1}}}, \\
f_{Z 1}=\frac{1}{2 \pi \sqrt{L_{N 1}\left(C_{N 1}+C_{P 1}\right)}} .
\end{gathered}
$$

As shown in Figure 3, the equivalent resistance of $1 / g_{m 1}$ and $r_{\mathrm{ds} 1}$ in parallel is approximately $1 / g_{m 1}$ for $r_{\mathrm{ds} 1} \gg 1 / g_{m 1}$. The amplitude $I_{N}$ is then expressed as

$$
I_{N}=I_{D} \frac{1}{1+g_{m 1} Z_{N}}=\frac{g_{m 1} V_{\mathrm{INN}}}{1+g_{m 1} Z_{N}},
$$

where $I_{D}$ is equal to $g_{m 1} V_{\text {INN }}$. Similarly, the current $I_{P}$ can be expressed by replacing $v_{\text {INN }}$ with $v_{\text {INP. }}$. The differential output current $I_{\text {out }}\left(=I_{P}-I_{N}\right)$ of the transconductance stage is simply obtained after replacing $v_{\mathrm{IN} P}$ with $v_{\mathrm{IN}}\left(=v_{\mathrm{IN} P}-\right.$ $v_{\text {INN }}$ ). The same LC parallel series combination with different impedance $L_{N 2}, C_{N 2}, C_{P 2}$ is applied in the transimpedance stage with $v_{\text {out }}\left(=v_{o 1}-v_{o 2}\right)$. Hence, the input impedance of the second LC stage is given by

$$
Z_{N 2}=\frac{1+s^{2} L_{N 2}\left(C_{N 2}+C_{P 2}\right)}{S\left(C_{N 2}+s^{2} L_{N 2} C_{P 2}\right)} .
$$

The resonant frequencies are expressed by

$$
\begin{gathered}
f_{P 2}=\frac{1}{2 \pi \sqrt{L_{N 2} C_{P 2}}}, \\
f_{Z 2}=\frac{1}{2 \pi \sqrt{L_{N 2}\left(C_{N 2}+C_{P 2}\right)}} .
\end{gathered}
$$

The differential output voltage of the transimpedance filter stage is then expressed by

$$
v_{\text {out }}=s L_{D} \frac{g_{m 1} Z_{N 2}}{1+g_{m 1} Z_{N 2}} I_{\text {out }} .
$$

When $f=f_{Z 1}$ then $Z_{N 1} \approx 0$. And when $f=f_{P 1}$ then $Z_{N 1} \approx$ $\infty$. Therefore, the output current $I_{\text {out }}=I_{P}-I_{N}$ in (4) can be expressed as

$$
I_{\text {out }} \approx \begin{cases}g_{m 1} v_{\mathrm{IN}} & \text { when } f=f_{Z 1}, \\ 0 & \text { when } f=f_{P 1}\end{cases}
$$

Similarly, $Z_{N 2} \approx 0$ when $f=f_{Z 2}$. And $Z_{N 2} \approx \infty$ when $f=f_{P 2}$. Hence the output voltage in (6) is given by

$$
v_{\text {out }} \approx \begin{cases}0 & \text { when } f=f_{Z 2}, \\ s L_{D} I_{\text {out }} & \text { when } f=f_{P 2} .\end{cases}
$$

It is observed from (9) and (10) that the transmission zero happens at $f_{P 1}$ in transconductance stage and happens

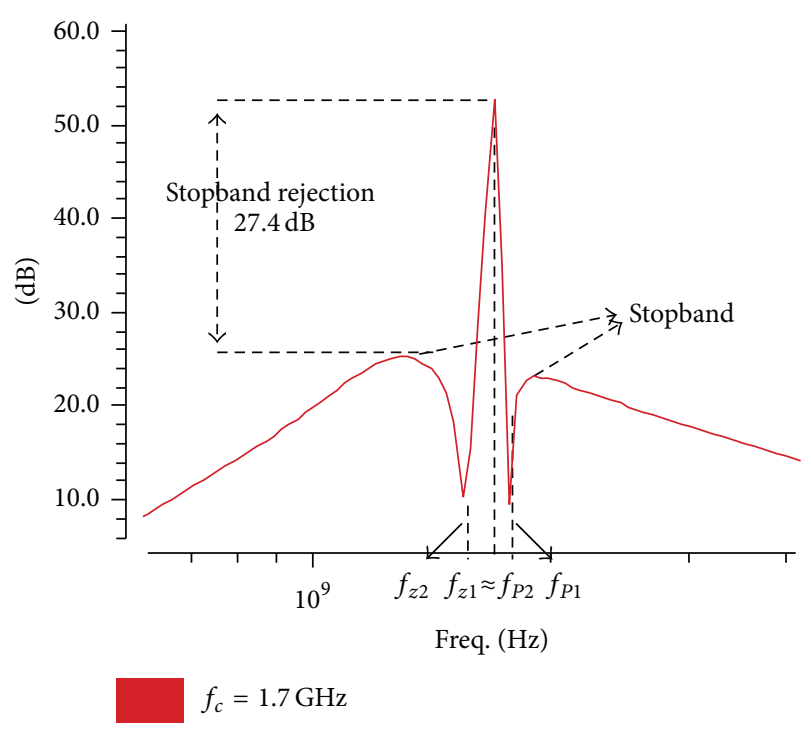

FIGURE 4: Example of frequency response of the proposed band pass filter $\left(f_{c}=1.7 \mathrm{GHz}, \mathrm{BW}=12.4 \mathrm{MHz}\right.$, and stopband rejection = $27.4 \mathrm{~dB})$.

at $f_{Z 2}$ in transimpedance stage. Meanwhile, the peak value happens at $f_{Z 1}$ in transconductance stage and happens at $f_{P 2}$ in transimpedance stage. Correspondingly, the peak conductance $g_{\max }$ and impedance $Z_{\max }$ are obtained at $f_{Z 1}$ and $f_{P 2}$. Finally, the overall transfer function of the BPF is obtained from (3) to (9). Consider

$$
v_{\mathrm{out}}=v_{\mathrm{IN}} \frac{g_{m 1}^{2} L_{D} Z_{N 2} s}{\left(1+g_{m 1} Z_{N 1}\right)\left(1+g_{m 1} Z_{N 2}\right)} .
$$

The peak output can be expressed in (12) when $f=f_{Z 1}$, and also $f_{Z 1} \approx f_{P 2}$. Consider

$$
v_{\text {out }} \approx \begin{cases}0 & \text { when } f=f_{P 1} \text { or } f_{Z 2}, \\ g_{\max } Z_{\max } v_{\mathrm{IN}} & \text { when } f=f_{Z 1} \approx f_{P 2},\end{cases}
$$

where $g_{\max }=I_{\text {out }} / v_{\text {IN }}$ and $Z_{\text {max }}=v_{\text {out }} / I_{\text {out }}=s L_{D}$.

From (12) the peak gain happens at center frequency (the pole $f_{P 2}$ and the zero $f_{Z 1}$ ). A wide tuning range is realized by changing $L_{N 1}$ and $L_{N 2}$. A high base band gain is achieved by maximizing $g_{\max }$ and $Z_{\max }$, which are determined by the $Q$ factor of the inductors and by location of the poles and zeros. The Q-factor of inductors is improved by using a cross-coupled transistor pair, creating negative impedance in parallel with the inductors. The location of poles and zeros can be adjusted by varying $C_{N}$ and $C_{P}$.

The pole frequency can be adjusted to be slightly greater than the zero frequency by making $C_{N 1}$ much less than $C_{P 1}$ and making $C_{N 2}$ much smaller than $C_{P 2}$. A steep roll-off can be achieved. Figure 4 demonstrates the frequency response of the proposed BPF at $f_{c}=1.7 \mathrm{GHz}$ and $\mathrm{BW}=12.4 \mathrm{MHz}$. Its stopband rejection is $27.4 \mathrm{~dB}$. Meanwhile, the peak center frequency gain can be increased when $f_{P 2} \approx f_{Z 1}$ by making $C_{N 1}+C_{P 1} \approx C_{P 2}$. 
Given: BPF (Figure 1) with NMOS $\left(m_{1}\right.$ to $\left.m_{17}\right)$, inductors $\left(L_{N 1}, L_{N 2}, L_{D}\right)$, capacitors $\left(C_{N}, C_{P 1}, C_{N 2}\right.$, and $\left.C_{P 2}\right)$, current sources $\left(I_{1}, I_{2}, I_{3}\right)$, power $(\mathrm{pw})$

Input: $V_{\text {inn }}$ and $V_{\text {in } p}$

Objective: BPF to meet a specified center frequency and bandwidth

Output: NMOS sizes, capacitors and inductors value

Design approach: //BPF design to meet the specified center frequency and bandwidth//

(1) Specify DC power $\left(\mathrm{pw}_{0}\right)$, center frequency $\left(f_{c 0}\right)$, bandwidth $\left(\mathrm{BW}_{0}\right)$;

(2) Calculate $I_{1}, I_{2}$ and $I_{3}$ based on $\mathrm{pw}_{0}$;

(3) Set $w_{3}, w_{4}, w_{5}$ based on $I_{1}, I_{2}$ and $I_{3}$;

(4) Set initial value $k_{3}(0), k_{4}(0)$ and $k_{5}(0)$;

(5) Given $C_{N 1}, C_{P 1}, C_{N 2}, C_{P 2}, L_{N 1}, L_{N 2}$ and $L_{D}$, set $C_{N 1} \ll C_{P 1}$ and $C_{N 2} \ll C_{P 2}$ to make $f_{p 1}$ a little greater than $f_{z 1}$ and make $f_{p 2}$ a little greater than $f_{z 2}$;

(6) $\quad i=0$ set $C_{p 2} \approx C_{p 1}+C_{n 1}$ to make $f_{p 2} \approx f_{z 1}$;

(7) while $(i<N) / /$ Optimize $k_{3}, k_{4}, k_{5}$ in $N$ iterations

(8) $\quad\left\{k_{3}(i)=k_{3}(0)+\left(k_{3 \max }-k_{3}(0)\right) * i / N\right.$;

$k_{4}(i)=k_{5}(i)=k_{4}(0)+\left(k_{4 \max }-k_{4}(0)\right) * i / N$;

(9) do DC simulation;

(10) if $\left|\mathrm{pw}-\mathrm{pw}_{0}\right| / \mathrm{pw}>0.01$ then $i=i+1$ and go to Step (7);

(11) else exit;

(12) end if\}

(13) adjust $C_{N 1}, C_{P 1}, C_{N 2}, C_{P 2}, L_{N 1}, L_{N 2}$; do AC simulation; //find $f_{c}$

(14) If $\left|f_{c}-f_{c 0}\right| / f_{c 0}<0.01$ then go to Step (17)

(15) else go to Step (13)

(16) end if;

(17) adjust $L_{D}$;

(18) do AC simulation; //find BW

(19) If $\left|\mathrm{BW}-\mathrm{BW}_{0}\right| / \mathrm{BW}_{0}<0.01$ then exit;

(20) else go to Step (17)

(21) end if;

Algorithm 1: A BPF design to meet the specified center frequency and bandwidth.

TABLE 1: Transistor size information.

\begin{tabular}{lccccccccccccccccc}
\hline Transistor & $m_{1}$ & $m_{2}$ & $m_{3}$ & $m_{4}$ & $m_{5}$ & $m_{6}$ & $m_{7}$ & $m_{8}$ & $m_{9}$ & $m_{10}$ & $m_{11}$ & $m_{12}$ & $m_{13}$ & $m_{14}$ & $m_{15}$ & $m_{16}$ & $m_{17}$ \\
\hline Width & $w_{1}$ & $w_{1}$ & $w_{6}$ & $w_{6}$ & $w_{4}$ & $k_{4} w_{4}$ & $k_{4} w_{4}$ & $w_{3}$ & $k_{3} w_{3}$ & $k_{3} w_{3}$ & $w_{2}$ & $w_{2}$ & $w_{7}$ & $w_{7}$ & $w_{5}$ & $k_{5} w_{5}$ & $k_{5} w_{5}$ \\
\hline Length & $L$ & $L$ & $L$ & $L$ & $L$ & $L$ & $L$ & $L$ & $L$ & $L$ & $L$ & $L$ & $L$ & $L$ & $L$ & $L$ & $L$ \\
\hline
\end{tabular}

\section{BPF Design with Fixed Center Frequency and Bandwidth}

Algorithm 1 presents sizing approach of BPF (Figure 1) in $180 \mathrm{~nm}$ CMOS process. The power supply is $1.8 \mathrm{~V}$. The desirable power consumption is denoted as $\mathrm{pw}_{0}$ while the desirable center frequency and bandwidth are denoted as $f_{c 0}$ and $\mathrm{BW}_{0}$, respectively. With the relationship of current mirror circuit, the current $I_{1}$ drives branch currents $I_{m 6}$ and $I_{m 7}$; the current $I_{2}$ drives branch currents $I_{m 9}$ and $I_{m 10}$; the current $I_{3}$ drives branch currents $I_{m 16}$ and $I_{m 17}$. Note that $I_{m x x}$ is the current through the transistor $m_{x x}$. Normally, the driver current $\left(I_{1}, I_{2}, I_{3}\right)$ is made by the tenth of its load current through transistor $\left(m_{6}, m_{7}, m_{9}, m_{10}, m_{16}, m_{17}\right)$ based on the power consumption pw.

The next step involves setting width and length of transistor $m_{1}$ to $m_{17}$ and multiplicand $k_{3}, k_{4}, k_{5}$ for current mirror load current through $m_{3}, m_{4}, m_{5}$, which is precalculated and summarized in Table 1 . The initial value for $k_{3}, k_{4}, k_{5}$ is 10 . It is then optimized to have the load current through transistor $\left(m_{6}, m_{7}, m_{9}, m_{10}, m_{16}, m_{17}\right)$ as $1 / 10$ of its driver current $\left(I_{1}, I_{2}\right.$, $\left.I_{3}\right)$.

Using $180 \mathrm{~nm}$ CMOS process, the value of $C_{1}$ to $C_{4}$ and $L_{1}$ to $L_{4}$ is calculated based on (2), (3), (6), and (7). Given $C_{N 1} \ll C_{P 1}$ and $C_{N 2} \ll C_{P 2}, f_{P 1}$ and $f_{P 2}$ are set to be a little greater than $f_{Z 1}$ and $f_{Z 2}$. Also, $f_{Z 1} \approx f_{P 2}$ if $C_{p 2} \approx$ $C_{p 1}+C_{n 1}$. The initial parameter setting is completed in steps 1-5 in Algorithm 1. As shown in Algorithm 1, $k_{3}, k_{4}$, and $k_{5}$ are optimized in step 8 till power consumption is met. Next, adjust $C_{N 1}$ to $C_{P 2}, L_{N 1}, L_{N 2}$ and do AC simulation until the center frequency $f_{c}$ is close to $f_{c 0}(<1 \%$ error). Finally, adjust $L_{D}$ and do AC simulation until the bandwidth $\mathrm{BW}$ is close to $\mathrm{BW}_{0}(<1 \%$ error $)$. 
Given: $f_{c}, \mathrm{BW}_{0}$, and initial values of $L_{N 1}, L_{N 2}, L_{D}$.

Input: $V_{\text {inn }}$ and $V_{\text {in } p}$

Objective: tunable BPF to meet $f_{c}$ and $\mathrm{BW}_{0}$

Output: $L_{N 1}, L_{N 2}, C_{P 2}$

Design approach: //Stage A to meet the specified $f_{c}$ (Steps (1)-(10))//

(1) Find the range of $f_{c}\left(f_{c 1}<f_{c}<f_{c 2}\right)$ in Table 2;

(2) Set initial values $L_{D}=L_{D 2}, L_{N 1}=L_{N 2}=L_{N 12}$, and set $C_{N 1}, C_{N 2}, C_{P 1}, C_{P 2}, \delta_{1}, \delta_{2}, \delta_{3}, M, N, P, Q$;

(3) Repeat

(4) do AC simulation;

(5) decrease $L_{N 1}=L_{N 2}$ by $\Delta L_{N 1}=\left(L_{N 12}-L_{N 11}\right) / M$;

(6) Until $\left|f-f_{c}\right|<\delta_{1}$;

(7) Repeat

(8) do AC simulation;

(9) decrease $C_{P 2}$ by $\Delta C=\left(C_{P 22}-C_{P 21}\right) / N$;

(10) Until $\left|f-f_{c}\right|<\delta_{2}$;

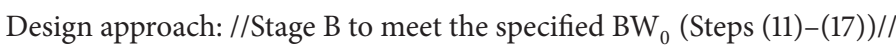

(11) Find $f_{c}$ and its corresponding $\mathrm{BW}_{\min }$ in Table 2;

(12) If $\mathrm{BW}_{0}<\mathrm{BW}_{\min }$ then break;

(13) Else

(14) Do \{

(15) decreases inductor $L_{D}$ by $\Delta L=\left(L_{D 2}-L_{D 1}\right) / P$;

(16) do AC simulation to find the bandwidth BW;

(17) $\}$ While $\left|\mathrm{BW}-\mathrm{BW}_{0}\right|<\delta_{3}$;

Design approach: //Stage $\mathrm{C}$ to calibrate BPF design after considering process variations (Steps (18)-(32))//

(18) Select $N$ (i.e., $N=100$ ) cases of BPF designs with different $f_{c 0}, \mathrm{BW}_{0}$ and $A_{V}$ after Stage $\mathrm{A}$ and $\mathrm{B}$;

(19) Perform Monte Carlo analysis to obtain $\mu$ and $\sigma$ for BW;

(20) Compute $(\mathrm{BW}-(\mu-\sigma))$; //calculate the BW deviation

(21) Choose top $30 \%$ cases having the worst BW deviation and find their center frequency $\left(f_{c}\right)$ and corresponding gain $\left(A_{v}\right)$;

(22) Compute the average of center frequency $\left(f_{\text {avg }}\right)$ and gain deviation $\left(\Delta A_{v}\right)$

(23) Compute $\Delta L_{D}$ from (17);

(24) For $i \leftarrow 1$ to $30 / /$ consider the top 30 cases

(25) $L_{D \_ \text {new }}(i)=L_{D_{\text {_old }}}(i)+\Delta L_{D}$;

(26) do AC simulation;

(27) if $\mathrm{BW}_{\text {new }}(i)>\mathrm{BW}_{\text {old }}(i)$ then set $\mathrm{BW}(i)=\mathrm{BW}_{\text {new }}(i)$;

(28) else $\left\{L_{D \_ \text {new }}(i)=L_{D_{-} \text {old }}(i)-\Delta L_{D}\right.$;

(29) do AC simulation;

(30) $\quad$ set $\left.\mathrm{BW}(i)=\mathrm{BW}_{\text {new }}(i)\right\}$;

(31) end if;

(32) End for;

Algorithm 2: Process variation aware tunable BPF design approach.

\section{Process Variation Aware Tunable BPF Design}

4.1. Tunable BPF with Specified Center Frequency and BW. The design approach described in Section 3 is sequential and iterative loops for parameter setting and sequential results are affecting one another. The final design meets unique specifications and its design parameters are difficult to be changed to become tunable for different center frequency or bandwidth. In this regard, a design approach to make BPF tunable is proposed, which stores BPF design parameters as design reference and increases design space for wide tuning frequency range.

The design approach for tunable BPF is divided into three stages. Stage A is to meet the center frequency $f_{c}$. Stage B is to meet the BW. Stage C is to calibrate the BPF design to meet $f_{c}$ and $\mathrm{BW}$ after process variations. They are shown in Figure 5. Algorithm 2 depicts detailed design approach in

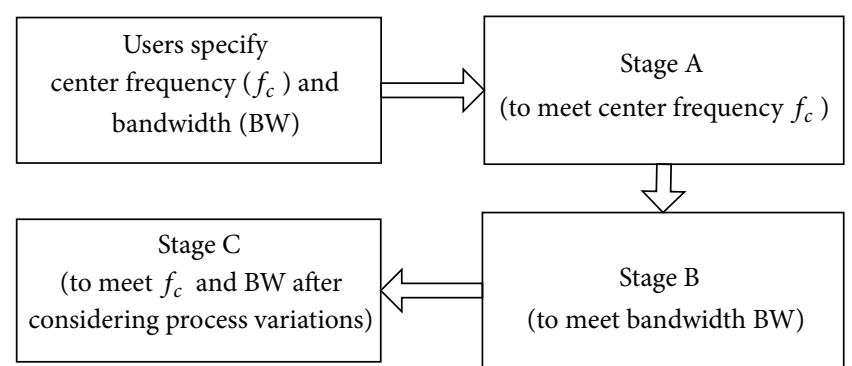

FIGURE 5: Block diagram of process variation aware tunable BPF design.

the three stages and explains how to obtain design parameters for the tunable BPF. In stage A, it is desirable to narrow the range of design parameters, which are primarily related to the center frequency. By referring to a look-up table of 
TABLE 2: Initial look-up table of inductors obtaining peak gain and minimum BW for different center frequencies.

\begin{tabular}{lccccc}
\hline $\begin{array}{l}L_{N 1} \\
(\mathrm{nH})\end{array}$ & $\begin{array}{c}L_{N 2} \\
(\mathrm{nH})\end{array}$ & $\begin{array}{c}L_{D} \\
(\mathrm{nH})\end{array}$ & $\begin{array}{c}f_{c} \\
(\mathrm{GHz})\end{array}$ & $\begin{array}{c}\mathrm{BW}_{\min } \\
(\mathrm{MHz})\end{array}$ & $\begin{array}{c}\text { Peak gain } \\
(\mathrm{dB})\end{array}$ \\
\hline 1.30 & 1.30 & 281.0 & 1.00 & 5.34 & 65.3 \\
1.10 & 1.10 & 269.4 & 1.07 & 5.47 & 69.3 \\
1.00 & 1.00 & 210.0 & 1.15 & 5.85 & 68.3 \\
0.90 & 0.90 & 196.0 & 1.20 & 6.33 & 64.7 \\
0.80 & 0.80 & 183.0 & 1.26 & 6.14 & 67.8 \\
0.70 & 0.70 & 169.0 & 1.35 & 6.87 & 66.2 \\
0.60 & 0.60 & 164.0 & 1.45 & 7.17 & 66.3 \\
0.50 & 0.50 & 136.0 & 1.58 & 7.79 & 66.1 \\
0.40 & 0.40 & 118.0 & 1.78 & 8.92 & 65.0 \\
0.30 & 0.30 & 93.00 & 2.04 & 9.91 & 64.9 \\
0.20 & 0.20 & 55.00 & 2.51 & 12.4 & 63.6 \\
0.10 & 0.10 & 27.50 & 3.55 & 16.6 & 63.1 \\
0.05 & 0.05 & 14.20 & 5.01 & 21.4 & 62.9 \\
\hline
\end{tabular}

inductors (Table 2), peak pass band gain and minimum BW for different center frequencies in a wide tuning frequency range are obtained. These parameters are obtained by design approach in Algorithm 1. Given $f_{c}$ to tunable BPF design, the first step is to find the adjacent center frequency (i.e., upper $f_{c 2}$ and lower $f_{c 1}$ ) from Table 2. Next, find the upper $L_{N 12}$ and lower inductor $L_{N 11}$ from $f_{c 2}$ and $f_{c 1}$, respectively. For example, if $f_{c}=1.7 \mathrm{GHz}$, then $f_{c 1}$ is $1.58 \mathrm{GHz}$ and $f_{c 2}$ is $1.78 \mathrm{GHz}$. Also, $L_{N 12}=0.5 \mathrm{nH}$ and $L_{N 11}=0.4 \mathrm{nH}$. Thereafter, set the initial value $L_{D}=L_{D 2}, L_{N 1}=L_{N 2}=L_{N 12}$. Calculate $C_{N 1}$ to $C_{P 2}$ value from equations in Section 2. Make $C_{P 22}=1.1 C_{P 2}, C_{P 21}=0.9 C_{P 2}$ and do AC simulation. $L_{N 1}$ and $L_{N 2}$ are the primary impact factors to determine the center frequency. If $\left|f-f_{c}\right|>\delta_{1}$ (i.e., $15 \mathrm{MHz}$ ), decrease $L_{1}$ and $L_{2}$ by $\Delta L_{N 1}=\left(L_{N 12}-L_{N 11}\right) / M$ and then conduct AC simulation. Otherwise, decrease the second primary impact factor $C_{P 2}$ by $\Delta C_{P 2}=\left(C_{P 22}-C_{P 21}\right) / N$ until $\left|f-f_{c}\right|<\delta_{2}$ (i.e., $1 \mathrm{MHz}$ ). Then, go to stage $B$ to meet the specified bandwidth, as shown in steps 11-17 in Algorithm 2. If BW $<\mathrm{BW}_{\min }$, then $\mathrm{BW}$ is out of design range. Otherwise, decrease $L_{D}$ by $\Delta L=\left(L_{D 2}-L_{D 1}\right) / P$ and do $\mathrm{AC}$ simulation till $\left|\mathrm{BW}-\mathrm{BW}_{0}\right|<\delta_{3}$ (i.e., $0.1 \mathrm{MHz}$ ).

Then, the specified BW is met. $M, N$, and $P$ are the number of repeats determined by the accuracy $\left(\delta_{1}, \delta_{2}, \delta_{3}\right)$ in simulation. Consider

$$
\begin{aligned}
\Delta L_{N 1} & =\frac{L_{\text {larger }}-L_{\text {smaller }}}{\text { number of repeats }}=\frac{L_{N 12}-L_{N 11}}{M}, \\
\Delta C_{P 2} & =\frac{C_{\text {larger }}-C_{\text {smaller }}}{\text { number of repeats }}=\frac{C_{p 22}-C_{p 21}}{N}, \\
\Delta L_{D} & =\frac{L_{\text {larger }}-L_{\text {smaller }}}{\text { number of repeats }}=\frac{L_{D 2}-L_{D 1}}{P},
\end{aligned}
$$

$$
\begin{gathered}
A_{v}=\frac{v_{\text {out }}}{v_{\mathrm{IN}}}=g_{\max } Z_{\max }=s g_{\max } L_{D}, \\
\left|\Delta A_{v}\right|=2 \pi f_{\text {avg }} g_{\max } \Delta L_{D} .
\end{gathered}
$$

4.2. Design Example of a Tunable BPF for $f_{c}(1.7 \mathrm{GHz})$ and $B W$ $(12.4 \mathrm{MHz})$. Table 3 summarizes transistor sizes and parameter settings based on the design approach in Section 3. Prior to implementing the tunable BPF design, the desirable center frequency $f_{c}(1.7 \mathrm{GHz})$ and $\mathrm{BW}(12.4 \mathrm{MHz})$ are specified. The number of repeats depends on the design accuracies $\delta_{1}, \delta_{2}$, and $\delta_{3}$. For example, $\delta_{1}, \delta_{2}$, and $\delta_{3}$ are given $15 \mathrm{MHz}, 1 \mathrm{MHz}$, and $0.1 \mathrm{MHz}$ and the number of repeats $M, N$, and $P$ is 20 , 40 , and 25. As shown in Table 2, the center frequency $f_{c}$ $(1.7 \mathrm{GHz})$ lies between $f_{c 1}(1.58 \mathrm{GHz})$ and $f_{c 2}(1.78 \mathrm{GHz})$, the corresponding inductor $L_{D}$ lies between $L_{D 1}(136 \mathrm{nH})$ and $L_{D 2}(118 \mathrm{nH})$, and the inductors $L_{N 1}$ and $L_{N 2}$ lie between $L_{N 11}(0.4 \mathrm{nH})$ and $L_{N 12}(0.5 \mathrm{nH})$. Therefore, set the initial value $L_{D}=L_{D 2}=136 \mathrm{nH}, L_{N 1}=L_{N 2}=L_{N 12}=0.5 \mathrm{nH}$, and $C_{N 1}=2 \mathrm{pF}, C_{P 1}=18 \mathrm{pF}, C_{N 2}=3 \mathrm{pF}, C_{P 2}=C_{N 1}+C_{P 1}=$ $20 \mathrm{pF}, C_{P 22}=1.1 C_{P 2}=22 \mathrm{pF}, C_{P 21}=0.9 C_{P 2}=18 \mathrm{pF}$ and do AC simulation. If $\left|f-f_{0}\right|>\delta_{1}(>15 \mathrm{MHz})$, decrease $L_{N 1}$ and $L_{N 2}$ by $\Delta L_{N 1}=\left(L_{N 12}-L_{N 11}\right) / M=0.005 \mathrm{nH}$ and then do AC simulation. Otherwise, decrease the second primary impact factor $C_{P 2}$ by $\Delta C_{P 2}=\left(C_{P 22}-C_{P 21}\right) / N=0.1 \mathrm{pF}$ until $\left|f-f_{c}\right|<\delta_{2}(<1 \mathrm{MHz})$. After the specified $f_{c}$ is met, then go to stage $\mathrm{B}$ to meet the specified $\mathrm{BW}=12.4 \mathrm{MHz}$.

As shown in steps 11-17 in Algorithm 2, the first step is to find $f_{c}$ and its corresponding bandwidth $\left(\mathrm{BW}_{\min }\right)$. If $\mathrm{BW}<\mathrm{BW}_{\min }$, then $\mathrm{BW}$ is out of range. If $\mathrm{BW}>\mathrm{BW}_{\min }$, decrease $L_{D}$ by $\Delta L=\left(L_{D 2}-L_{D 1}\right) / P=0.84 \mathrm{nH}$ and run $\mathrm{AC}$ simulation. Repeat until $\left|\mathrm{BW}-\mathrm{BW}_{0}\right|<\delta_{3}(<0.1 \mathrm{MHz})$. Then, $f_{c}(1.7 \mathrm{GHz})$ and $\mathrm{BW}(12.4 \mathrm{MHz})$ are met. The proposed BPF provides a high pass band gain between 45.2 and $65.1 \mathrm{~dB}$ and tunable pass band between 5.5 and $51.2 \mathrm{MHz}$, while the center frequency is varied from 1.0 to $2.04 \mathrm{GHz}$, which is depicted in Figure 6.

4.3. BPF Calibration after Process Variations. The BPF design calibration to meet the specified BW after process variation is presented in stage $C$ in Algorithm 2. The initial step in stage $\mathrm{C}$ is to select $N$ (i.e., $N=100$ ) cases of different $f_{c}$, BW, and $A_{V}$ and conduct Monte Carlo simulation to obtain BW's mean $(\mu)$ and standard deviation $(\sigma)$. The top $30 \%$ design cases contributing to the worst deviation of (BW $(\mu-\sigma))$ are selected to calculate the average center frequency $\left(f_{\text {avg }}\right)$ and the corresponding gain deviation $\left(\Delta A_{v}\right)$. Then, $\Delta L_{D}$ can be calculated from (17). Note that $\Delta L_{D}$ is used to calibrate $L_{D}$, which in turn calibrates BW. Finally, calibrated $L_{D}$ and calibrated BW for each case are obtained. Table 4 shows the tunable BPF BW comparison with and without calibration after process variations. Ten design cases of center frequency which varied from 1 to $2.04 \mathrm{GHz}$ are compared. Their BW is close to $12.3 \mathrm{MHz}$. Considering the case example of $f_{c}=1.35 \mathrm{GHz}$ and $\mathrm{BW}=12.2 \mathrm{MHz}$ in Table 4 , the bandwidth deviation $\mathrm{BW}-(\mu-\sigma)$ before calibration is $0.88 \mathrm{MHz}$ and after calibration is $0.42 \mathrm{MHz}$, which accounts for $52.3 \%$ improvement. Consider all 10 case examples, the average bandwidth deviation $\mathrm{BW}-(\mu-\sigma)$ before calibration is 
TABle 3: Transistor size and parameter setting.

\begin{tabular}{|c|c|c|c|c|c|c|c|c|}
\hline $\begin{array}{l}m_{1} \\
\text { (um) }\end{array}$ & $\begin{array}{c}m_{2} \\
\text { (um) }\end{array}$ & $\begin{array}{c}m_{3} \\
\text { (um) }\end{array}$ & $\begin{array}{c}m_{4} \\
\text { (um) }\end{array}$ & $\begin{array}{c}m_{5} \\
\text { (um) }\end{array}$ & $\begin{array}{c}m_{6} \\
\text { (um) }\end{array}$ & $\begin{array}{c}m_{7} \\
\text { (um) }\end{array}$ & $\begin{array}{c}m_{8} \\
\text { (um) }\end{array}$ & $\begin{array}{c}m_{9} \\
\text { (um) }\end{array}$ \\
\hline 150 & 150 & 2 & 2 & 2 & 19 & 19 & 4 & 46.4 \\
\hline $\begin{array}{l}m_{10} \\
\text { (um) }\end{array}$ & $\begin{array}{c}m_{11} \\
\text { (um) }\end{array}$ & $\begin{array}{l}m_{12} \\
\text { (um) }\end{array}$ & $\begin{array}{l}m_{13} \\
\text { (um) }\end{array}$ & $\begin{array}{l}m_{14} \\
\text { (um) }\end{array}$ & $\begin{array}{l}m_{15} \\
\text { (um) }\end{array}$ & $\begin{array}{l}m_{16} \\
\text { (um) }\end{array}$ & $\begin{array}{l}m_{17} \\
\text { (um) }\end{array}$ & $\begin{array}{c}L \\
\text { (um) }\end{array}$ \\
\hline 46.4 & 90 & 90 & 2 & 2 & 2 & 19 & 19 & 180 \\
\hline$M$ & $N$ & $P$ & $\begin{array}{c}\delta_{1} \\
(\mathrm{MHz})\end{array}$ & $\begin{array}{c}\delta_{2} \\
(\mathrm{MHz})\end{array}$ & $\begin{array}{c}\delta_{3} \\
(\mathrm{MHz})\end{array}$ & $\begin{array}{c}I_{1} \\
(\mathrm{~mA})\end{array}$ & $\begin{array}{c}I_{2} \\
(\mathrm{~mA})\end{array}$ & $\begin{array}{c}I_{3} \\
(\mathrm{~mA})\end{array}$ \\
\hline 20 & 40 & 25 & 15 & 1 & 0.1 & 50 & 300 & 50 \\
\hline
\end{tabular}

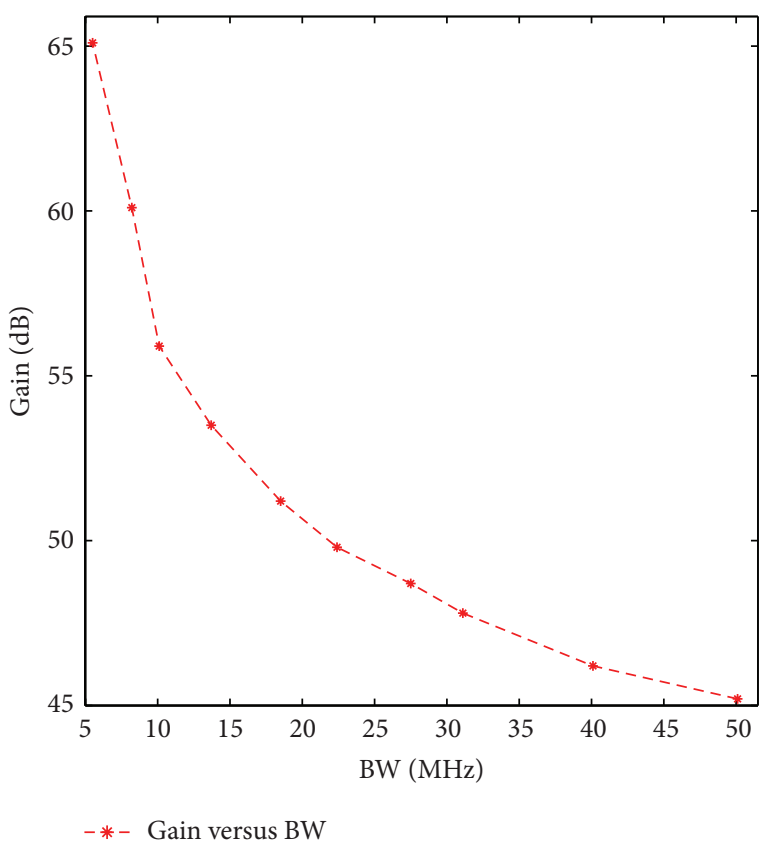

FIgURE 6: Pass band gain versus tunable bandwidth (45.2 dB $\leq A_{V} \leq$ $65.1 \mathrm{~dB}, 5.5 \mathrm{MHz} \leq \mathrm{BW} \leq 51.2 \mathrm{MHz}$ ) for $1.0 \mathrm{GHz} \leq f_{c} \leq 2.04 \mathrm{GHz}$.

$0.58 \mathrm{MHz}$ and after calibration is $0.292 \mathrm{MHz}$, which accounts for $49.6 \%$ improvement.

\section{Measurement and Performance Analysis}

The performance of ten tunable BPF designs with the pass band nearly constant $(12.1-12.6 \mathrm{MHz})$ is shown in Table 5. The bandwidth is $12.1 \mathrm{MHz}, 12.3 \mathrm{MHz}, 12.1 \mathrm{MHz}$, $12.1 \mathrm{MHz}, \quad 12.2 \mathrm{MHz}, \quad 12.3 \mathrm{MHz}, \quad 12.2 \mathrm{MHz}, \quad 12.4 \mathrm{MHz}$, $12.5 \mathrm{MHz}, 12.6 \mathrm{MHz}$, and $12.6 \mathrm{MHz}$, respectively. The center frequency is varied from 1.0 to $2.04 \mathrm{GHz}: 1.0 \mathrm{GHz}, 1.07 \mathrm{GHz}$, $1.15 \mathrm{GHz}, 1.20 \mathrm{GHz}, 1.26 \mathrm{GHz}, 1.35 \mathrm{GHz}, 1.45 \mathrm{GHz}, 1.58 \mathrm{GHz}$, $1.78 \mathrm{GHz}$, and $2.04 \mathrm{GHz}$. The nominal pass band gain before considering process variations is between 53.4 and $59.9 \mathrm{~dB}$. Considering process variations on $t_{\mathrm{ox}}, L_{\mathrm{eff}}$, and $v_{t}$ with a maximum $10 \%$ variation on their nominal values, the Monte Carlo simulation results show robustness of the BPF:
TABLE 4: Tunable BPF BW comparison with and without calibration after process variations.

\begin{tabular}{|c|c|c|c|c|c|}
\hline \multirow{2}{*}{$\begin{array}{l}f_{c} \\
(\mathrm{GHz})\end{array}$} & \multirow{2}{*}{$\begin{array}{l}\text { BW } \\
(\mathrm{MHz})\end{array}$} & \multicolumn{2}{|c|}{$\mu-\sigma$} & \multicolumn{2}{|c|}{$\mathrm{BW}-(\mu-\sigma)$} \\
\hline & & $\begin{array}{c}\text { w/o } \\
\text { calibration }\end{array}$ & $\begin{array}{c}\mathrm{w} \\
\text { calibration }\end{array}$ & $\begin{array}{c}\text { w/o } \\
\text { calibration }\end{array}$ & $\begin{array}{c}\mathrm{w} \\
\text { calibration }\end{array}$ \\
\hline 1.00 & 12.1 & 11.15 & 11.56 & 0.95 & 0.54 \\
\hline 1.07 & 12.3 & 10.96 & 11.52 & 1.34 & 0.78 \\
\hline 1.15 & 12.1 & 12.51 & 12.34 & -0.41 & -0.24 \\
\hline 1.20 & 12.2 & 11.24 & 11.62 & 0.96 & 0.58 \\
\hline 1.26 & 12.3 & 11.25 & 11.85 & 1.05 & 0.45 \\
\hline 1.35 & 12.2 & 11.32 & 11.78 & 0.88 & 0.42 \\
\hline 1.45 & 12.4 & 11.83 & 12.09 & 0.57 & 0.31 \\
\hline 1.58 & 12.5 & 12.15 & 12.39 & 0.35 & 0.11 \\
\hline 1.78 & 12.6 & 12.81 & 12.74 & -0.21 & -0.14 \\
\hline 2.04 & 12.6 & 12.27 & 12.49 & 0.33 & 0.11 \\
\hline
\end{tabular}

zero deviation on center frequency. The average maximum deviation on pass band gain is $1.16 \mathrm{~dB}$ on a nominal pass band gain of $55.6 \mathrm{~dB}$. And the average maximum deviation on bandwidth is $1.06 \mathrm{MHz}$ on a nominal bandwidth of 12.3 MHz.

Table 6 summarizes the calibrated performance of the ten tunable BPF designs after process variations. Figure 7 shows a low noise figure $(<6 \mathrm{~dB})$, while the center frequency is varied from 1.0 to $2.04 \mathrm{GHz}$.

\section{Conclusion}

This paper presented an effective design approach to optimize design parameters of a BPF to achieve tunable center frequency and bandwidth in a wide frequency span, for example, $1.04 \mathrm{GHz}$. Process variations on channel length, physical oxide thickness, and threshold voltage were considered in Monte Carlo simulation. The BPF design calibration to compensate bandwidth deviation from process variations was presented and evaluated. Considering process variations in $180 \mathrm{~nm}$ CMOS process and the central frequency which varied from 1.0 to $2.04 \mathrm{GHz}$, it was shown in Table 6 that the BW deviation $\left(\mathrm{BW}_{\sigma}\right)$ is $0.292 \mathrm{MHz}$ on the pass band mean $\left(\mathrm{BW}_{\mu}\right)$ of $12.01 \mathrm{MHz}$. The pass band gain variation $\left(A_{v(\sigma)}\right)$ is 


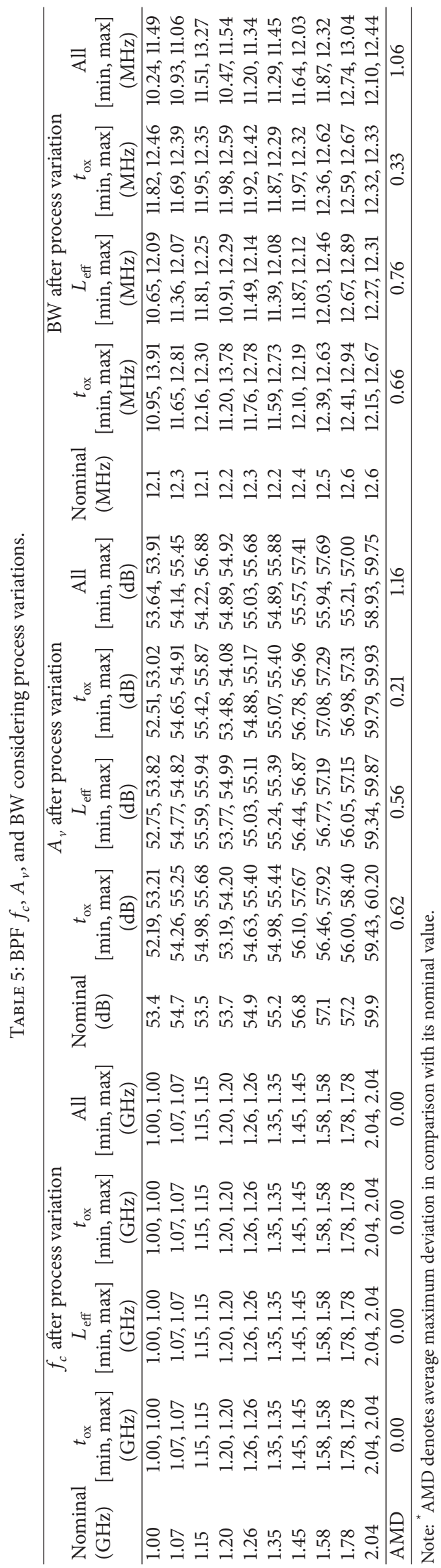




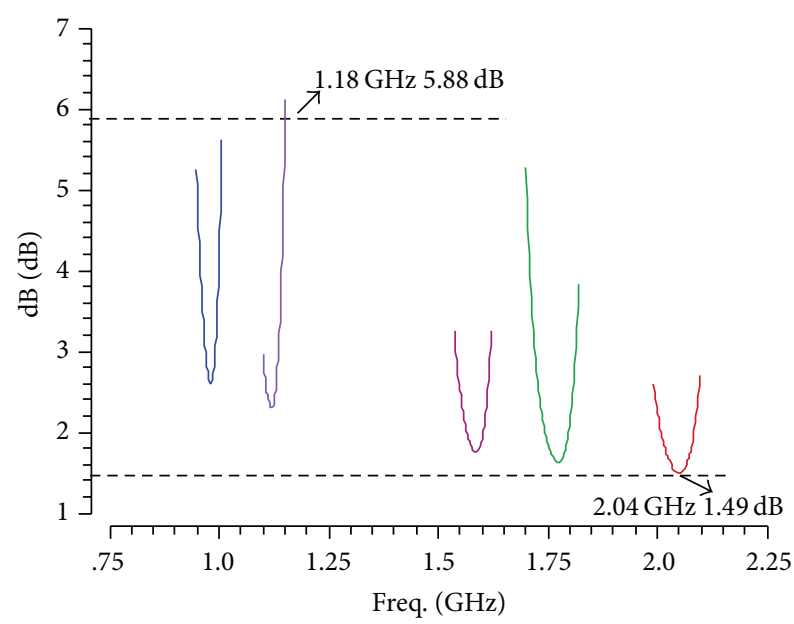

$$
\begin{aligned}
& \mathrm{NF}\left(f_{c}=1.0 \mathrm{GHz}\right) \\
& \mathrm{NF}\left(f_{c}=1.18 \mathrm{GHz}\right) \\
& \mathrm{NF}\left(f_{c}=1.58 \mathrm{GHz}\right)
\end{aligned}
$$

FIGURE 7: Noise figure measurement for different center frequencies.

TABLE 6: Calibrated performance after process variation for the ten tunable BPF designs in Table 5.

\begin{tabular}{lc}
\hline Parameter & Our work \\
\hline CMOS technology $(\mathrm{nm})$ & 180 \\
Filter order & 4 \\
Supply voltage $(\mathrm{V})$ & 1.8 \\
Frequency tuning range $(\mathrm{GHz})$ & $1.0-2.04$ \\
BW mean $\left(\mathrm{BW}_{\mu}\right)(\mathrm{MHz})$ & 12.01 \\
BW deviation $\left(\mathrm{BW}_{\sigma}\right)(\mathrm{MHz})$ & 0.292 \\
Pass band gain mean $\left(A_{v(\mu)}\right)(\mathrm{dB})$ & 55.02 \\
Pass band gain deviation $\left(A_{v(\sigma)}\right)(\mathrm{dB})$ & 0.58 \\
NF $(\mathrm{dB})$ & $<6$ \\
Power $(\mathrm{mW})$ & 15 \\
\hline
\end{tabular}

$0.58 \mathrm{~dB}$ on the pass band gain mean $\left(A_{v(\mu)}\right)$ of $55.02 \mathrm{~dB}$. Low noise figure $(<6 \mathrm{~dB})$ and steep roll-off high stopband rejection $(>20 \mathrm{~dB})$ make the tunable BPF attractive in reconfigurable $\mathrm{RF}$ and cognitive radio in TV band applications.

\section{Conflict of Interests}

The authors declare that there is no conflict of interests regarding the publication of this paper.

\section{References}

[1] A. S. Hussaini, R. Abd-Alhameed, and J. Rodriguez, "Tunable RF filters: survey and beyond," in Proceedings of the 18th IEEE International Conference on Electronics, Circuits and Systems (ICECS '11), pp. 512-515, December 2011.

[2] C. Barth, I. R. Linscott, and U. S. Inan, "A double notch RF filter architecture for SAW-less GPS receivers," in Proceedings of the IEEE International Symposium of Circuits and Systems (ISCAS '11), pp. 1804-1807, May 2011.
[3] S. A. Vallese, A. Bevilacqua, C. Sandner, M. Tiebout, A. Gerosa, and A. Neviani, "Analysis and design of an integrated notch filter for the rejection of interference in UWB systems," IEEE Journal of Solid-State Circuits, vol. 44, no. 2, pp. 331-343, 2009.

[4] H. Lee, H. Seo, I. Choi, T. Chung, D. Jeong, and B. Kim, "A RF CMOS band-pass tracking filter with enhanced Q and high linearity," in Proceedings of the Asia-Pacific Microwave Conference (APMC '11), pp. 1901-1904, December 2011.

[5] J. Robert Tourret, S. Amiot, M. Bernard et al., "SiP tuner with integrated LC tracking filter for both cable and terrestrial TV reception," IEEE Journal of Solid-State Circuits, vol. 42, no. 12, pp. 2809-2821, 2007.

[6] A. N. Mohieldin, E. Sánchez-Sinencio, and J. Silva-Martínez, "A 2.7-V 1.8-GHz fourth-order tunable LC bandpass filter based on emulation of magnetically coupled resonators," IEEE Journal of Solid-State Circuits, vol. 38, no. 7, pp. 1172-1181, 2003.

[7] H. Le-Thai, H. H. Nguyen, H. N. Nguyen, H. S. Cho, J. S. Lee, and S. G. Lee, "An IF bandpass filter based on a low distortion transconductor," IEEE Journal of Solid-State Circuits, vol. 45, no. 11, pp. 2250-2261, 2010.

[8] F. Dülger, E. Sánchez-Sinencio, and J. Silva-Martínez, "A 1.3-V 5 -mW fully integrated tunable bandpass filter at $2.1 \mathrm{GHz}$ in 0.35 $\mu \mathrm{m}$ CMOS," IEEE Journal of Solid-State Circuits, vol. 38, no. 6, pp. 918-928, 2003.

[9] A. X. He and W. B. Kuhn, "A 2.5-GHz low-power, high dynamic range, self-tuned Q-enhanced LC filter in SOI," IEEE Journal of Solid-State Circuits, vol. 40, no. 8, pp. 1618-1628, 2005.

[10] Y. Sun, C. J. Jeong, I. Y. Lee, J. S. Lee, and S. G. Lee, "A 50$300-\mathrm{MHz}$ low power and high linear active RF tracking filter for digital TV tuner ICs," in Proceedings of the IEEE Custom Integrated Circuits Conference (CICC '10), pp. 1-4, San Jose, Calif, USA, September 2010.

[11] B. Georgescu, I. G. Finvers, and F. Ghannouchi, "2 GHz Qenhanced active filter with low passband distortion and high dynamic range," IEEE Journal of Solid-State Circuits, vol. 41, no. 9, pp. 2029-2039, 2006.

[12] A. El Oualkadi, M. El Kaamouchi, J.-M. Paillot, D. Vanhoenacker-Janvier, and D. Flandre, "Fully integrated high$\mathrm{Q}$ switched capacitor bandpass filter with center frequency and bandwidth tuning," in Proceedings of the IEEE Radio Frequency Integrated Circuits Symposium (RFIC '07), pp. 681-684, June 2007.

[13] A. Ghaffari, E. A. M. Klumperink, M. C. M. Soer, and B. Nauta, "Tunable high-Q N-path band-pass filters: modeling and verification," IEEE Journal of Solid-State Circuits, vol. 46, no. 5, pp. 998-1010, 2011.

[14] T. A. Vu, S. Sudalaiyandi, H. A. Hjortland, O. Nass, and T. S. Lande, "An inductorless 3-5 GHz band-pass filter with tunable center frequency in $90 \mathrm{~nm}$ CMOS," in Proceedings of the IEEE International Symposium on Circuits and Systems (ISCAS '13), pp. 1284-1287, IEEE, Beijing, China, May 2013.

[15] M. Darvishi, R. van der Zee, E. A. M. Klumperink, and B. Nauta, "Widely tunable 4th order switched gm-C band-pass filter based on N-path filters," IEEE Journal of Solid-State Circuits, vol. 47, no. 12, pp. 3105-3119, 2012. 

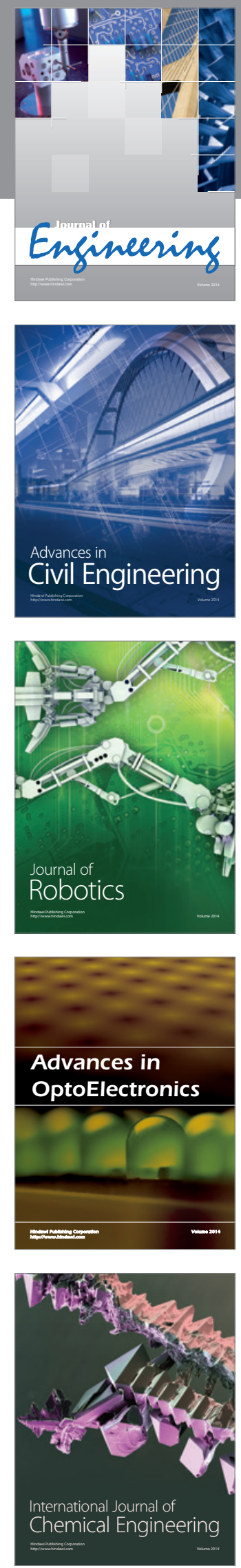

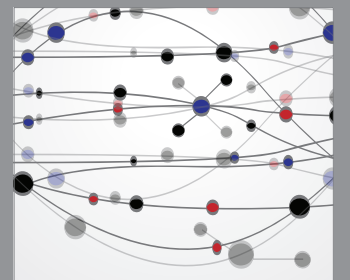

The Scientific World Journal
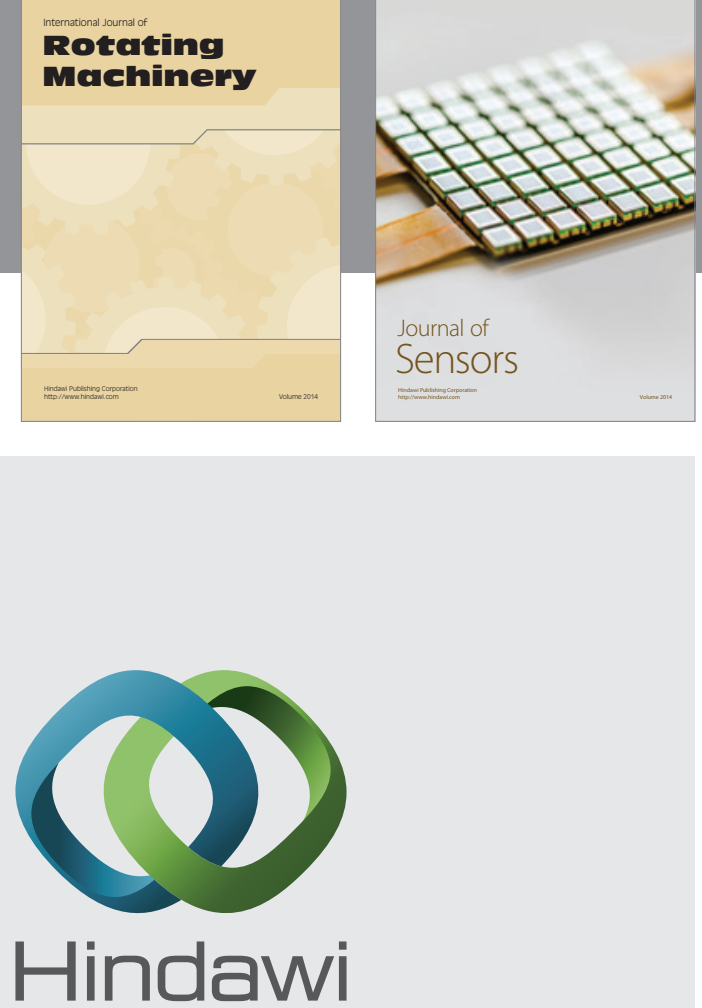

Submit your manuscripts at http://www.hindawi.com
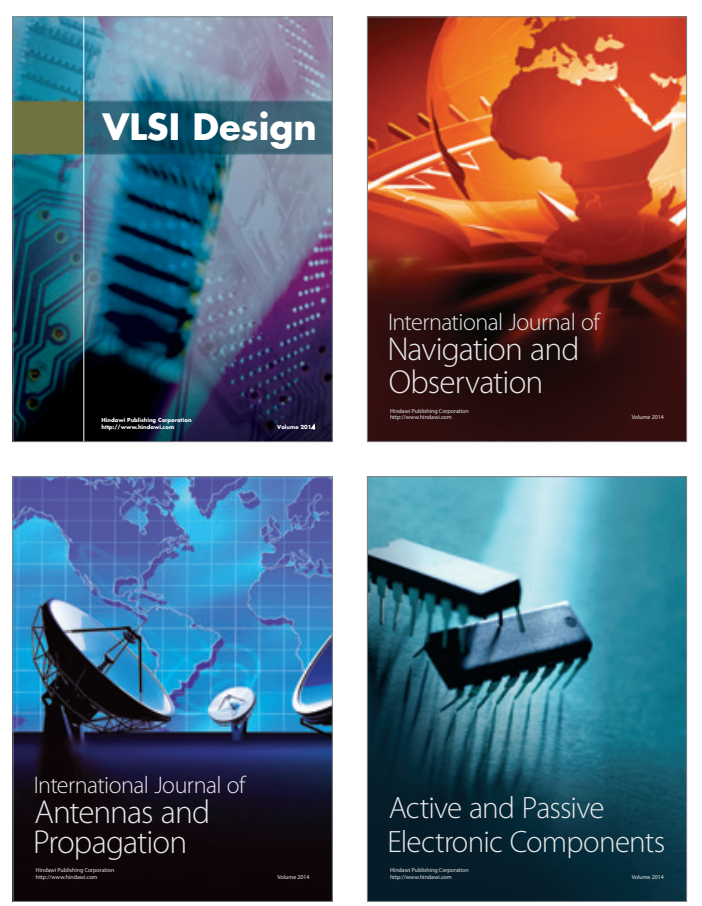
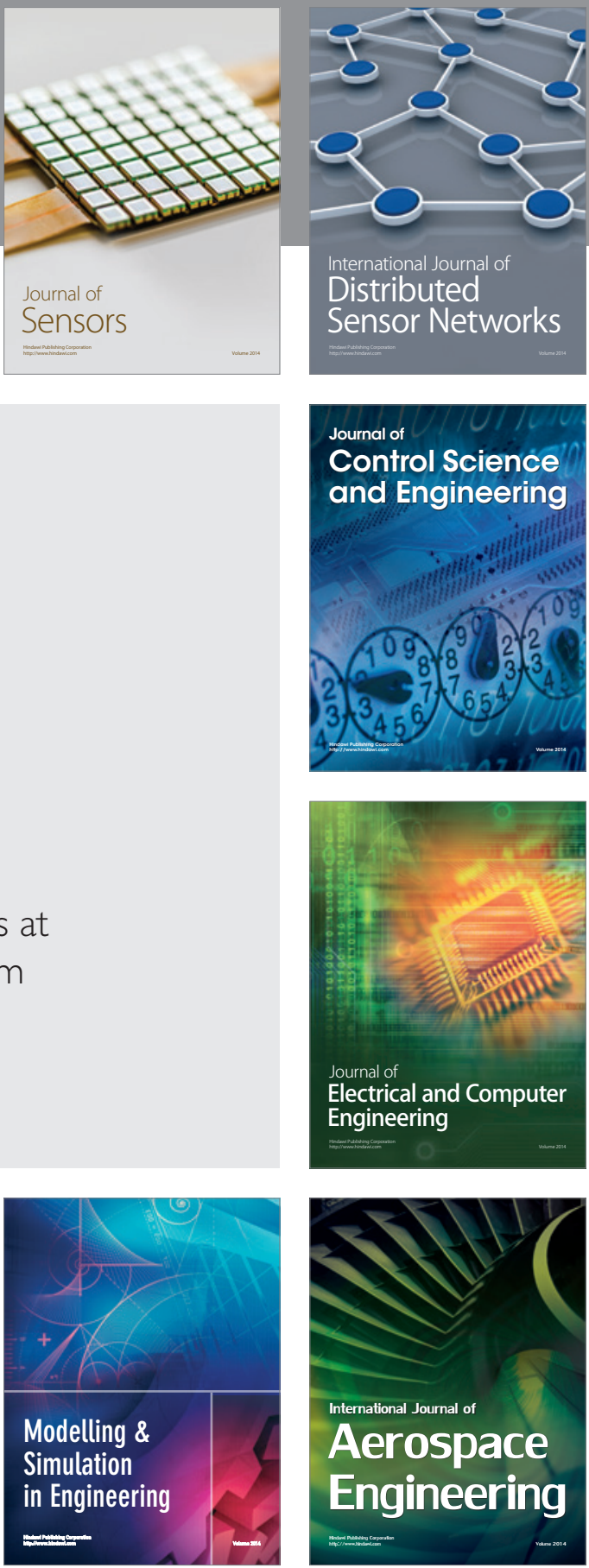

Journal of

Control Science

and Engineering
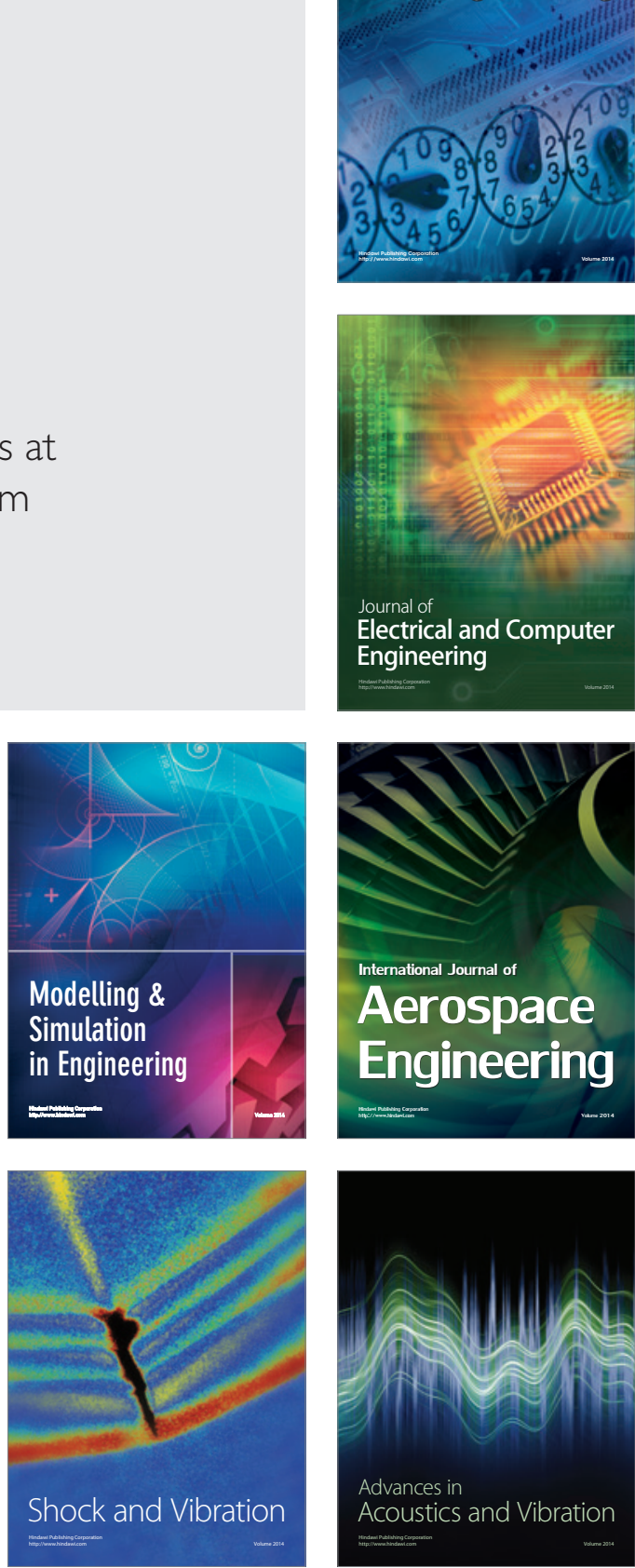